\title{
Spring phenology shapes the spatial foraging behavior of Antarctic petrels
}

\author{
Per Fauchald ${ }^{1, *}$, Arnaud Tarroux ${ }^{2}$, Torkild Tveraa ${ }^{1}$, Yves Cherel ${ }^{3}$, Yan Ropert-Coudert ${ }^{3}$, \\ Akiko Kato $^{3,4}$, Oliver P. Love ${ }^{5}$, Øystein Varpe ${ }^{6,7}$, Sébastien Descamps ${ }^{2}$ \\ ${ }^{1}$ Norwegian Institute for Nature Research, Fram Centre, 9296 Tromsø, Norway \\ ${ }^{2}$ Norwegian Polar Institute, Fram Centre, 9296 Tromsø, Norway \\ ${ }^{3}$ Centres d'Etudes Biologiques de Chizé, UMR7372 du CNRS-Université de La Rochelle, 79360 Villiers-en-Bois, France \\ ${ }^{4}$ Institut Pluridisciplinaire Hubert Curien, CNRS UMR7178, 67037 Strasbourg, France \\ ${ }^{5}$ Department of Biological Sciences, University of Windsor, Windsor, ON N9B 3P4, Canada \\ ${ }^{6}$ The University Centre in Svalbard, 9171 Longyearbyen, Norway \\ ${ }^{7}$ Akvaplan-niva, Fram Centre, 9296 Tromsø, Norway
}

\begin{abstract}
In polar seas, the seasonal melting of ice triggers the development of an open-water ecosystem characterized by short-lived algal blooms, the grazing and development of zooplankton, and the influx of avian and mammalian predators. Spatial heterogeneity in the timing of ice melt generates temporal variability in the development of these events across the habitat, offering a natural framework to assess how foraging marine predators respond to the spring phenology. We combined $4 \mathrm{yr}$ of tracking data of Antarctic petrels Thalassoica antarctica with synoptic remote-sensing data on sea ice and chlorophyll a to test how the development of melting ice and primary production drive Antarctic petrel foraging. Cross-correlation analyses of first-passage time revealed that Antarctic petrels utilized foraging areas with a spatial scale of $300 \mathrm{~km}$. These areas changed position or disappeared within 10 to $30 \mathrm{~d}$ and showed no spatial consistency among years. Generalized additive model (GAM) analyses suggested that the presence of foraging areas was related to the time since ice melt. Antarctic petrels concentrated their search effort in melting areas and in areas that had reached an age of 50 to $60 \mathrm{~d}$ from the date of ice melt. We found no significant relationship between search effort and chlorophyll a concentration. We suggest that these foraging patterns were related to the vertical distribution and profitability of the main prey, the Antarctic krill Euphausia superba. Our study demonstrates that the annual ice melt in the Southern Ocean shapes the development of a highly patchy and elusive food web, underscoring the importance of flexible foraging strategies among top predators.
\end{abstract}

KEY WORDS: Area-restricted search $\cdot$ Euphausia superba $\cdot$ Marginal ice zone $\cdot$ Phytoplankton biomass $\cdot$ Procellariiformes $\cdot$ Sea ice dynamics $\cdot$ Southern Ocean $\cdot$ Thalassoica antarctica

\section{INTRODUCTION}

The phenology of plants and animals is governed by seasonal abiotic events causing predictable changes in favorable conditions for reproduction and growth (Visser \& Both 2005, Forrest \& Miller-Rushing 2010). In marine ecosystems, important phenological events, such as the spring bloom or the seasonal reproduction in key species, propagate through the food web

\footnotetext{
${ }^{*}$ Corresponding author: per.fauchald@nina.no
}

with widespread consequences for ecosystem functioning. The seasonal advance and retreat of sea ice make the environmental fluctuations in polar seas particularly strong, causing extreme seasonal variations in physical conditions (Brierley \& Thomas 2002, Moline et al. 2008, Ji et al. 2013). In winter, the sea ice around Antarctica extends to cover almost 20 million $\mathrm{km}^{2}$, and is one of the largest and most dynamic ecosystems on Earth (Brierley \& Thomas 2002). The

(C) The authors 2017. Open Access under Creative Commons by Attribution Licence. Use, distribution and reproduction are unrestricted. Authors and original publication must be credited. 
ice pack is the substrate for ice algae, bacteria, and grazing zooplankton, and is also an important nursery habitat for Antarctic krill Euphausia superba (hereinafter: krill), offering protection from air-breathing surface predators (Brierley et al. 2002). By seeding, fertilizing, and stabilizing the surface water, the ice melt in spring initiates the characteristically shortlived and patchy phytoplankton blooms (Smith \& Nelson 1985, Mitchell \& Holm-Hansen 1991, Brierley \& Thomas 2002). Spring blooms are an important food source for krill, and swarms of feeding krill are targets for a large number of predators, including seabirds, pinnipeds, and cetaceans (Fraser \& Hofmann 2003, Smetacek \& Nicol 2005, Murphy et al. 2007). Much of the distribution range of krill is covered by seasonal or permanent ice, and the timing and intensity of their reproduction is significantly affected by the amount of sea ice and the timing of ice retreat (Quetin \& Ross 2001, Atkinson et al. 2004, Kawaguchi et al. 2007). Predation pressure on krill from air-breathing predators intensifies during summer, possibly forcing the krill to deeper water and decoupling them from their phytoplankton food source (Ainley et al. 2015). Hereinafter, we term the timing of the sequence of ecosystem events initiated by the melting of sea ice the spring phenology. The vast ice sheet around Antarctica does not melt synchronously. Thus at a given date in spring, different areas will have reached different stages in spring phenology. For example, some areas may be in the growth phase, some areas may be at the peak, while others could be in the diminishing phase of the phytoplankton bloom. To predators, the different phenological stages are likely to offer different levels of availability and profitability of prey items. The spatial development of ice melt will accordingly reflect a heterogeneous and transient distribution of favorable foraging areas, and mobile predators are expected to respond to this heterogeneity by modifying their habitat utilization and search pattern for food.

In this study, we test the prediction that the foraging activity of Antarctic petrels Thalassoica antarctica in the Weddell Sea is related to the spring phenology. In spring and summer, Antarctic petrels forage over vast ice-filled or previously ice-filled areas, conducting hierarchical searches (Fauchald 1999) in a patchy, scale-dependent, and transient prey field (Fauchald \& Tveraa 2006). We hypothesize that Antarctic petrels increase their foraging effort in areas characterized by a favorable phenological stage. Accordingly, as the season progresses, we would expect Antarctic petrels to change foraging areas to keep the phenological stage of their habitat in a phase that maximizes access to profitable prey. Krill is a dominant prey item for Antarctic petrels during the breeding season (Lorentsen et al. 1998), and as a surface-feeding predator, we expect the Antarctic petrel to be especially sensitive to changes in the vertical distribution of krill. Because we expect krill to descend to deeper waters as the season progresses (Ainley et al. 2015), we would expect Antarctic petrels to increase their search effort in areas at an early phenological stage, i.e. around the ice melt. To examine this hypothesis, we used remotesensing data to investigate the spatial pattern of ice melt and the subsequent phenological development of surface chlorophyll a ( $\mathrm{chl} \mathrm{a}$ ). We used tracking data to examine the foraging patterns of Antarctic petrels, the predictability of their foraging areas, and how their foraging effort was related to surface chl a concentration and time elapsed since ice melt.

\section{MATERIALS AND METHODS}

\section{Antarctic petrels}

The eastern Weddell Sea is the foraging area of Antarctic petrels Thalassoica antarctica breeding at Svarthamaren ( $71^{\circ} 53^{\prime} \mathrm{S}, 5^{\circ} 10^{\prime} \mathrm{E}$ ) (Lorentsen et al. 1998, Fauchald \& Tveraa 2006). Svarthamaren is a nunatak (a mountain peak protruding above the ice sheet) situated approximately $200 \mathrm{~km}$ inland in Antarctica, and is the largest known colony of Antarctic petrels, hosting ca. 200000 breeding pairs (Descamps et al. 2016). The Antarctic petrel lays its egg when the adjacent ocean is still heavily covered with sea ice. By hatching and early chick-guarding time in late January, the massive sea ice sheet has broken up, and foraging occurs over mostly open water until early March, when fledging occurs. Both parents take part in chick-feeding, and krill dominate the prey brought back to the chick (Lorentsen et al. 1998).

\section{Argos and GPS tracking of Antarctic petrels}

Antarctic petrels were tracked in 4 different years using Argos satellite transmitters (1996-1997 season) and GPS tags (2011-2014; Table 1). To exclude wrong locations, a basic speed filter was applied on all tracks. Locations situated above the Antarctic ice cap or ice shelf (i.e. non-foraging habitat) were also excluded (see Fauchald \& Tveraa 2006, Tarroux et al. 2016 for details). A polar stereographic projection with $0^{\circ}$ longitude and $70^{\circ}$ standard parallel was used throughout the study. 
Table 1. Summary statistics of Antarctic petrel Thalassoica antarctica foraging trips during 4 breeding seasons. Number of individuals fitted with PTT tags in 1996-1997 and GPS tags in 2011-2014 are given in parentheses for the number of trips. Mean, median and min.-max. values are shown for other foraging trip characteristics. \% ice cover: in the habitat at the start of the trip. Max. dist. colony: maximum distance from colony; FPT: first-passage time

\begin{tabular}{|c|c|c|c|c|c|}
\hline & & 1996-1997 & 2011-2012 & $2012-2013$ & $2013-2014$ \\
\hline No. of trips (tagged ind.) & & $55(22)$ & $17(14)$ & $48(46)$ & $68(67)$ \\
\hline \multirow[t]{3}{*}{ Start of trip (date) } & Mean & $1 \mathrm{Feb}$ & 9 Jan & 24 Jan & $24 \mathrm{Dec}$ \\
\hline & Median & $27 \mathrm{Jan}$ & 9 Jan & 23 Jan & $19 \mathrm{Dec}$ \\
\hline & Date range & $20 \mathrm{Jan}-28 \mathrm{Feb}$ & $13 \mathrm{Dec}-7$ Feb & 26 Dec-11 Feb & 29 Nov-22 Jan \\
\hline \multirow[t]{3}{*}{ Trip duration (d) } & Mean & 7.5 & 9.6 & 5.7 & 10.4 \\
\hline & Median & 6.6 & 7.8 & 5.1 & 10.2 \\
\hline & Min.-max. & $2-17$ & $2.6-21.4$ & $2-15.2$ & $1.6-27.4$ \\
\hline \multirow[t]{3}{*}{ Trip distance (km) } & Mean & 4171 & 3744 & 2709 & 3330 \\
\hline & Median & 3909 & 3961 & 2377 & 2759 \\
\hline & Min.-max. & 868-10 809 & $587-6453$ & $692-7863$ & $368-9480$ \\
\hline \multirow[t]{3}{*}{ Max. dist. colony (km) } & Mean & 1047 & 1253 & 853 & 920 \\
\hline & Median & 1160 & 1581 & 760 & 817 \\
\hline & Min.-max. & $261-2524$ & $336-1765$ & $340-1931$ & $327-2061$ \\
\hline \multirow[t]{3}{*}{ Ice cover (\%) } & Mean & 7.9 & 32.6 & 14.3 & 44.3 \\
\hline & Median & 8 & 28 & 13 & 48 \\
\hline & Min.-max. & $6-10$ & $13-61$ & $10-29$ & $22-73$ \\
\hline \multirow[t]{3}{*}{ FPT radius $(\mathrm{km})$} & Mean & 91.5 & 60.7 & 65.0 & 50.2 \\
\hline & Median & 80 & 56 & 51 & 40 \\
\hline & Min.-max. & $20-220$ & $7.5-222$ & $5-263$ & $5-219$ \\
\hline
\end{tabular}

\section{6-1997 data}

From 18 to 20 January, 36 Antarctic petrels were equipped with satellite platform terminal transmitters (PTTs) at their nest. PTTs (PTT100, 20 and $30 \mathrm{~g}$; Microwave Telemetry) were attached to the back of the birds with a harness covered with TeXon padding during their last guarding spell. The weight of the device carried by each bird represented on average 3.2 and $4.7 \%$ (20 and $30 \mathrm{~g} \mathrm{PTTs}$, respectively) of their average body mass. The weight was accordingly slightly larger than the $3 \%$ rule proposed by Phillips et al. (2003), suggesting that a detrimental effect with respect to the cost of flight, foraging success, and mass gain during the foraging bout could be expected (Passos et al. 2010, Vandenabeele et al. 2012). Harnesses and transmitters were removed from the birds as they returned to the colony. Eight birds did not return to the colony and 6 either lost their transmitter at an early stage or the transmitter failed to give signals (see Fauchald \& Tveraa 2006). In the final dataset, only trips with a defined area-restricted search (ARS) were included (see 'FPT analyses' below). According to this procedure, 3 trips were removed from the sample, and the final filtered dataset comprised 5436 positions from 55 trips and 22 individual birds. Using the location error estimates provided by Pinaud \& Weimerskirch (2005), the average location error in the dataset was estimated as $14.2 \mathrm{~km}$ (Fauchald \& Tveraa 2006). Median time interval between successive Argos locations was 99 min (95\% interquantiles: 15-426 min).

\section{1-2014 data}

A total of 131 individuals were tagged with miniaturized GPS units (CatTrack 1, Catnip Technologies) during both the brooding and chick-rearing stages. The GPS units, weighing ca. $20 \mathrm{~g}$, were mounted on the 2 central rectrices using black Tesa tape, and removed when the bird returned to the colony. Data were then downloaded, projected, and speedfiltered in order to exclude aberrant locations (Tarroux et al. 2016). Four GPS units failed a few hours after the birds had left the colony and did not contain usable data. The filtered GPS dataset consisted of 132353 locations from 133 tracks and 127 individuals. First-passage time (FPT) calculations indicated that ARS was present for all 133 tracks (see 'FPT analyses' below). By testing 3 units at a known location in the breeding colony, an average location error was estimated as $48 \mathrm{~m}$ (95\% confidence interval [CI]: 14-81 m). Median time interval between successive GPS locations was $10 \mathrm{~min}$ (95\% interquantiles: 5-30 $\mathrm{min}$ ). 
We defined the available foraging habitat as the ocean area within a radius of $2000 \mathrm{~km}$ from the colony (Fig. 1), amounting to 7.1 million $\mathrm{km}^{2}$, excluding landmasses and the ice shelf. Percentage ice cover in the foraging habitat at the start of each trip varied between 6 and $73 \%$. In total, the trips covered a distance of $>660000 \mathrm{~km}$, and $>99 \%$ of the positions were recorded within areas with either a seasonal or multi-year ice cover (Fig. 1). Although there was considerable overlap, data from different years covered different periods of the breeding season (Table 1). Most notably, 1996-1997 covered the chick-rearing period while most of the trips in 2013-2014 took place during the brooding period.

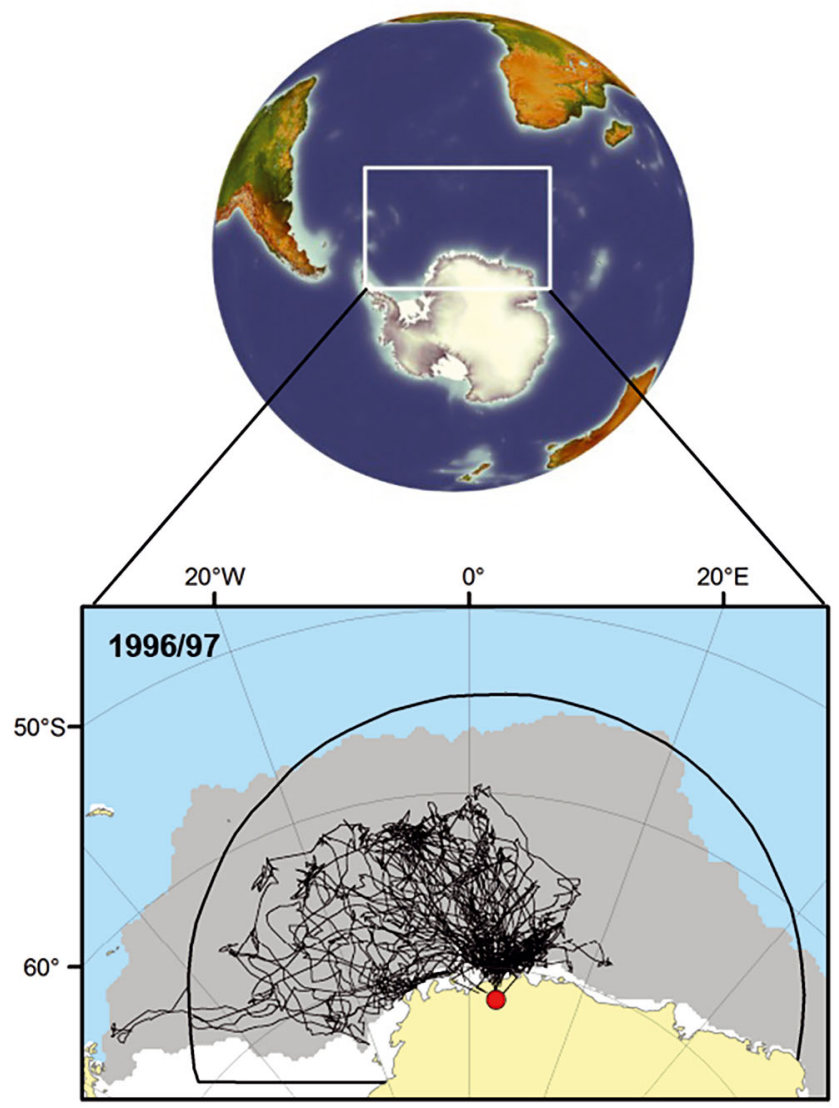

\section{Sea ice data and date of ice melt}

Data on sea ice concentration were obtained from the National Snow and Ice Data Center (http://nsidc. org/data/NSIDC-0079/versions/2). Measures of sea ice concentrations were derived from passive microwave measurements from satellites using the daily bootstrap estimates of ice concentration from Nimbus-7 SMMR and DMSP SSM/I-SSMIS, version 2 (Comiso 2000). Ice cover in the study area is at a max-
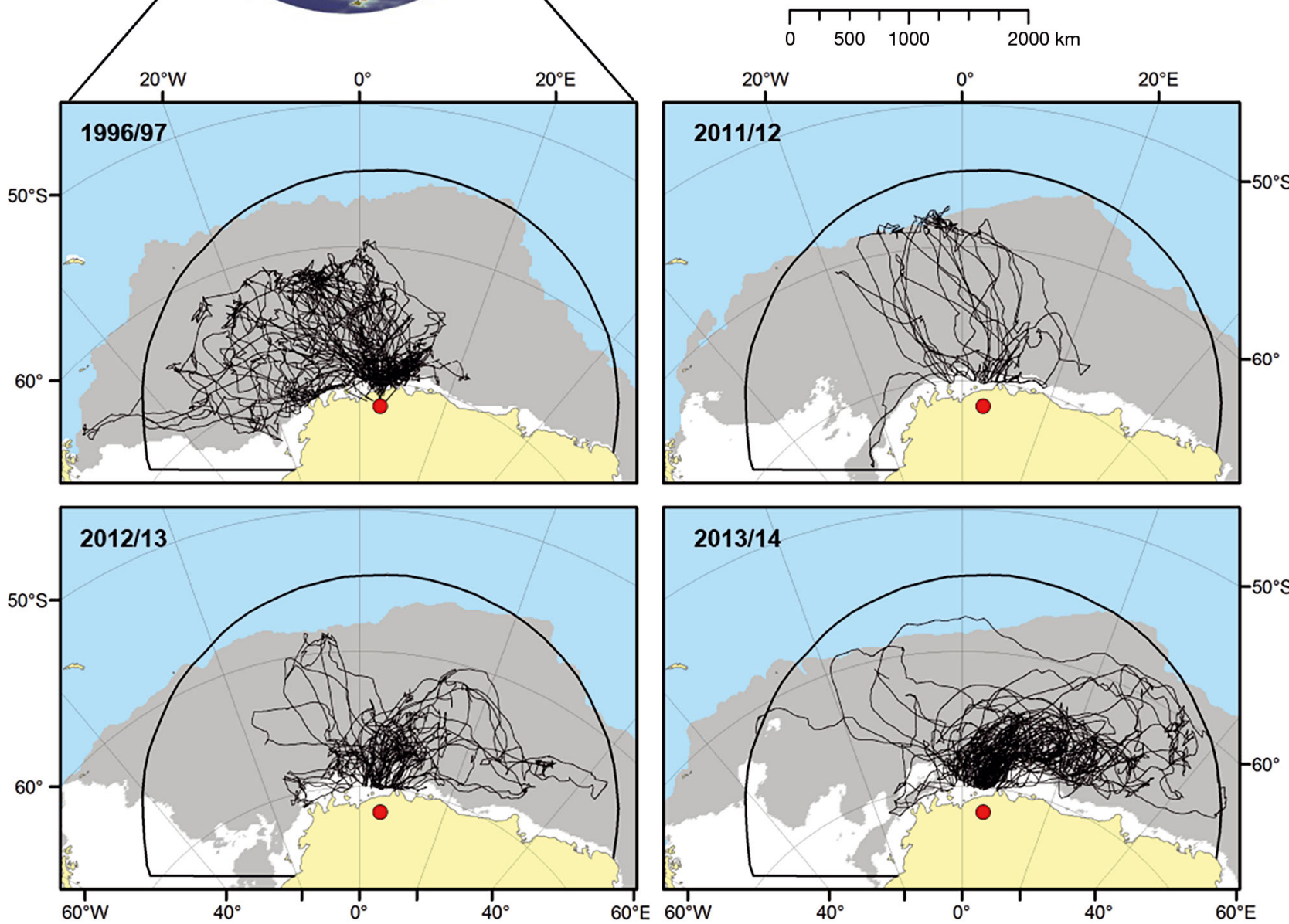

Fig. 1. Study area, foraging trips of Antarctic petrels Thalassoica antarctica (black lines), and seasonal ice habitat in the 4 study periods. Light blue: areas with open water throughout the year (maximum ice cover <15\%). Grey: area with seasonal ice cover ( $>15 \%$ ice cover on 1 November and open water during summer). White: ice cap or multi-year ice (>50\% ice cover on 15 March). Black arc (radius $=2000 \mathrm{~km}$ from the breeding colony): the defined foraging habitat. Red dot: breeding colony 
imum in September and at a minimum in March. Sea ice data were obtained for the period 31 October15 March, thus covering the period of ice melting. For each of the study periods, data were retrieved for each cell in a $25 \times 25 \mathrm{~km}^{2}$ grid covering the Antarctic petrel's foraging habitat.

For each grid cell, the date of ice melt was defined by following the ice development forward from 31 October and backward from 15 March (see e.g. Stammerjohn et al. 2008 for a similar procedure). The forward date of ice melt was defined as the first occurrence of a $7 \mathrm{~d}$ running mean ice concentration of $<50 \%$. Similarly, the backward date of ice melt was defined as the last occurrence of a $7 \mathrm{~d}$ running mean ice concentration of $>50 \%$. In $90 \%$ of the cases, the forward and backward dates of ice melt coincided, indicating a relatively rapid diminishing of the ice cover with a distinct date of ice melt. In cases where the time period between the forward and backward dates of ice melt was $<30 \mathrm{~d}$, the midpoint was used as the defined date of ice melt. Otherwise, the date of ice melt was defined as unknown.

\section{Chlorophyll data}

Daily chl a concentration data $\left(\mathrm{mg} \mathrm{m}^{-3}\right)$ for the years 2011-2014 were obtained from the SeaWiFS dataset hosted by NOAA's CoastWatch Program and NASA's Goddard Space Flight Center, OceanColor Web (http://oceancolor.gsfc.nasa.gov; O'Reilly et al. 1998). Chl a data were unavailable for the 1996-1997 season. Although cloud cover was generally heavy in the study area, limiting the datasets for each year, values of chl a were assigned to $32 \%$ of the bird positions in the 3 study periods when chl a data were available, amounting to a total of $78758 \mathrm{~km}$ of tracks. Chl a data could therefore be used to (1) give a general picture of the spring bloom phenology in the defined habitat in relation to the time since ice melt, and (2) investigate the foraging response of Antarctic petrels to variation in concentration of chl a in the 2011-2012, 2012-2013, and 2013-2014 seasons.

\section{FPT analyses}

FPT (first-passage time) is defined as the time required for an animal to cross a circle of a given radius $(r)$ and can be used to measure the scale-dependent search effort along a foraging track (Fauchald \& Tveraa 2003, Bailey \& Thompson 2006, Freitas et al. 2008, Pinaud 2008, Iversen et al. 2014). Each foraging trip was analyzed separately. To ensure that points along the tracks were equally represented (Pinaud 2008), locations were interpolated to obtain a uniform distance interval of $2 \mathrm{~km}$ (Fauchald \& Tveraa 2006, Hamer et al. 2009). Based on the interpolated locations, the variance in log-transformed FPT was calculated for $r$ ranging from 2 to $300 \mathrm{~km}$. The $r$ giving the maximum variance in log FPT has been termed the ARS scale (Pinaud \& Weimerskirch 2005), and corresponds to the spatial scale at which the animal concentrates its search effort. It is also the scale that best differentiates between high and low FPT along the path (Fauchald \& Tveraa 2006). A maximum variance was undefined in 3 of the 191 tracks (1.6\%), i.e. the variance in log FPT decreased continuously throughout the range of $r$, suggesting that these birds performed an indistinctive ARS or did not use ARS in their search. These trips were therefore excluded from the sample (see also Fauchald \& Tveraa 2006). For the remaining 188 trips, FPT values were calculated for each interpolated point along the track using the $r$ equal to the trip-specific observed ARS scale.

\section{Spatial predictability of foraging areas}

To investigate whether the variation in individual FPT values reflected common foraging grounds, and furthermore, to measure the spatial scale, the duration, and the year-to-year predictability of such areas, spatial and temporal correlograms of the standardized FPT values among trips were computed (see Fauchald \& Tveraa 2006). First, FPT values from each trip were aggregated successively along the paths on a $50 \times 50 \mathrm{~km}^{2}$ grid. For each trip, the $\log _{10}$ of the aggregated FPT values were $Z$-scored (mean: $0, \mathrm{SD}: 1$ ). Pearson's correlation coefficients were calculated for all possible pairs of the standardized FPT values among different trips within given distances and time intervals. For spatial cross-correlograms, time interval was kept constant and within \pm 2 d. For temporal cross-correlograms, distance interval was kept constant and equal to 0-100 km. Cross-correlograms were calculated within and among breeding seasons. Days since 31 October was used to calculate the seasonal lags among years.

The $95 \%$ CIs for cross-correlation coefficients were calculated by a delete-one jackknife procedure (Efron \& Tibshirani 1993) using trip as the independent statistical unit. Accordingly, the jackknife standard error was calculated on cross-correlation coefficients where 1 trip was left out of the sample at a time (see Fauchald \& Tveraa 2006). 


\section{Foraging effort and habitat characteristics}

Generalized additive models (GAMs) were used to analyze how the foraging pattern of Antarctic petrels in terms of FPT changed in response to the stage in spring phenology as indicated by the time since ice melt and the concentration of chl a. Partly because chl a data were only available for 3 of the 4 study periods and partly because there was a relatively close relationship between the ice melt pattern and chl a values (see 'Results'), analyses were done separately for the 2 predictor variables. To investigate how the search effort changed as new stages of phenology became available during the course of the season, the percentage of ice present in the available foraging habitat at the start of each trip was included as an interaction term in the analyses.

The dataset used in the analysis of response to phenology was compiled by identifying the grid cell from the ice data that overlapped with the corresponding interpolated FPT points, and calculating the time since ice melt (see 'Sea ice data and date of ice melt' above). The resulting dataset comprised 176 trips from 4 study periods covering a total length of $513076 \mathrm{~km}$. For the chl $a$ analyses, all data on chl $a$ within $\pm 5 \mathrm{~d}$ and $0-$ $100 \mathrm{~km}$ from the FPT point were assigned by interpolated distance weighing (IDW). Chl a data were missing in areas with continuous ice and areas with cloud cover, reducing the sample to $32 \%$ of the original bird positions. However, the dataset used in analyses of chl a still comprised 107 trips from 3 study periods and covering a total length of $78758 \mathrm{~km}$.

To reduce spatial dependencies in the response variable, FPT values from each trip were aggregated on pre-defined intervals of the predictor variable. Thus, 1 observation in the dataset represented the average response in FPT during a trip for a given interval in the predictor variable. For the analyses of the response to spring phenology, FPT values for each trip were averaged on $1 \mathrm{~d}$ intervals in time since ice melt. For chl a analyses, FPT values for each trip were averaged on 0.1 intervals in the $\log _{10}$-transformed values of chl a. Finally, to remove systematic differences in FPT values among trips in the datasets, the $\log _{10}$-transformed FPT values were $Z$-scored for each trip. The dataset on time since ice melt comprised 2634 observations from 176 trips, with median number of observations (levels of predictors) per trip equal to 15 (min.: 1, max.: 28). The dataset on chl a comprised 2941 observations from 107 trips, with median number of observations (levels of predictors) per trip equal to 26 (min.: 3, max.: 55).
We expected non-linear foraging responses to $\mathrm{chl} a$ and time since ice melt, and the FPT values were accordingly fitted to GAMs using the mgcv library (Wood 2006) in R 3.2.2 (R Development Core Team 2016). Moreover, we expected the responses to change during the course of the season, and we therefore included percentage ice cover in the foraging habitat at the start of the trip as an interaction term. This was done by modeling the predictor as a 2-dimensional smooth function where the predictor variable (time since ice melt or chl a) was combined with percentage ice cover in the habitat. A thin-plate regression spline was used as the basis, and the optimal degree of smoothing was defined by generalized cross-validation (GCV).

Confidence intervals for the response were calculated by a bootstrap procedure using trip as the independent statistical unit. For each analysis, 10000 bootstrap samples were drawn from the sample of foraging trips (176 and 107 trips for the phenology and chl a analyses, respectively). GAM analysis was conducted on each bootstrap sample, and the predicted value for each level of the predictors were calculated using the predict function in mgcv. Finally, from the predicted bootstrap values, we calculated the mean and $95 \%$ CI for the response.

\section{RESULTS}

\section{Seasonal changes in habitat characteristics}

The available foraging habitat of Antarctic petrels breeding at Svarthamaren changed substantially in terms of ice cover and chl a concentration during the course of the breeding cycle (Fig. 2). At the time of egg-laying, the area had an ice cover of $45-80 \%$; by hatching time, this cover was reduced to $15-30 \%$; and during chick-feeding, ice cover was $<20 \%$. Ice cover and timing of melting varied among years, although the same general pattern remained (Fig. 2A). While highly variable both within and among years, the average seasonal change in chl $a$ within the foraging habitat indicated an increase in phytoplankton biomass from early December through mid-January (ca. hatching time) and a decrease thereafter (Fig. 2B).

The relationship between chl $a$ and the time since ice melt (Fig. 3) revealed a more consistent pattern than the relationships with date in the season (Fig. 2). On average, the data indicated a rapid increase in chl a concentration from the time of ice melt, reaching a maximum approximately 20 to $40 \mathrm{~d}$ after ice melt and decreasing thereafter (Fig. 3). It is important 


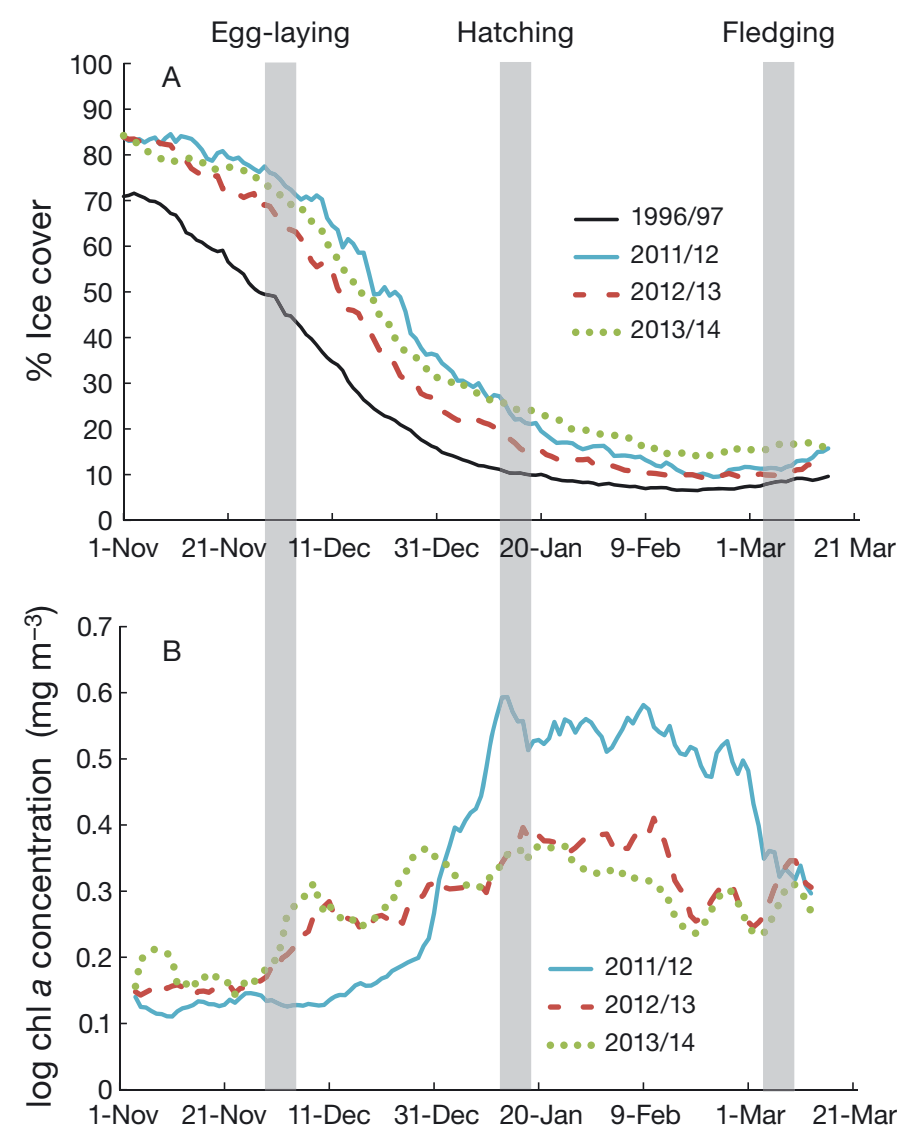

Fig. 2. Seasonal development of (A) percentage ice cover and (B) average chl a concentration (5 d running mean) in the available foraging habitat for Antarctic petrels Thalassoica antarctica breeding in the colony of Svarthamaren. Grey bars: approximate timing of major breeding events. Chl a data were not available for the 1996-1997 season

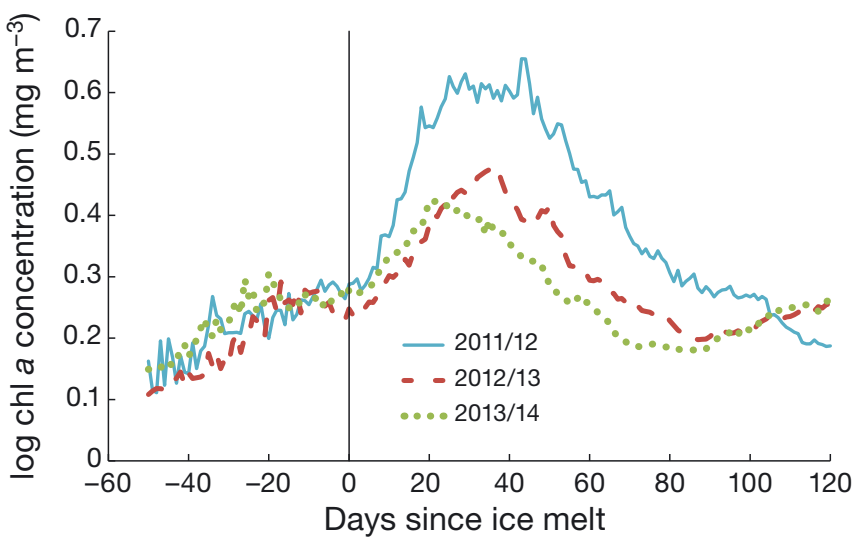

Fig. 3. Relationship between average chl a concentration and time since ice melt in the available foraging habitat for Antarctic petrels Thalassoica antarctica breeding in the colony of Svarthamaren. Chl a values were averaged over days since ice melt, irrespective of the date in the season. Chl a data were not available for the 1996-1997 season to note that this pattern reflects the average pattern in cloud-free open waters, and does not necessarily reflect the development of individual blooms in the particular foraging areas used.

Within the foraging habitat, the date of ice melt varied from 6 November to 15 February (Fig. 4). Generally, ice melt was later the further south. However, the pattern of ice melt was highly variable both within and among years (Fig. 4), suggesting a spatial heterogeneity in the stages of spring phenology available to foraging Antarctic petrels.

\section{ARS and spatial predictability of foraging areas}

The cross-correlation in FPT among trips for distances $<50 \mathrm{~km}$ and time lags $<2 \mathrm{~d}$ was significantly positive (Pearson's correlation coefficient $=0.31$, $95 \%$ CI: 0.21-0.40) (Fig. 5). Correlations were significantly positive for distances $<300 \mathrm{~km}$, suggesting that Antarctic petrels increased their foraging effort in overlapping areas at a scale of $\sim 300 \mathrm{~km}$ (Fig. 5A). This pattern was absent when computing the crosscorrelogram among seasons (Fig. 5C), suggesting that the foraging areas were not spatially consistent among the breeding seasons.

Correlations between FPT among trips within the same area (distance $<100 \mathrm{~km}$ ) decreased with increasing time lag, suggesting that foraging areas were transient also within the season (Fig. 5B). Pearson's correlation coefficient leveled off at a value of approximately 0.1 , with a confidence interval overlapping zero, after $10 \mathrm{~d}$. Again, the correlations among different seasons were close to zero (Fig. 5D), independent of differences between dates, suggesting little predictability in foraging areas among breeding seasons.

\section{Foraging response to spring phenology}

The GAM of the standardized FPT as a function of time since ice melt and percentage ice cover in the habitat by the start of the trip showed a relatively low (adjusted $\mathrm{R}^{2}=0.085, \mathrm{n}=2634$ ) and complex (estimated degrees of freedom [edf] $=22.2$ ) fit. The response with respect to time since ice melt for high $(50 \%)$, medium $(30 \%)$, and low $(10 \%)$ ice cover in the habitat is shown in Fig. 6. Bootstrap analysis (Fig. 6) suggested a significant response under heavy ice cover early in the season (Fig. 6A) and under low ice cover late in the season (Fig. 6C), while the response was weak in the transitional period with 

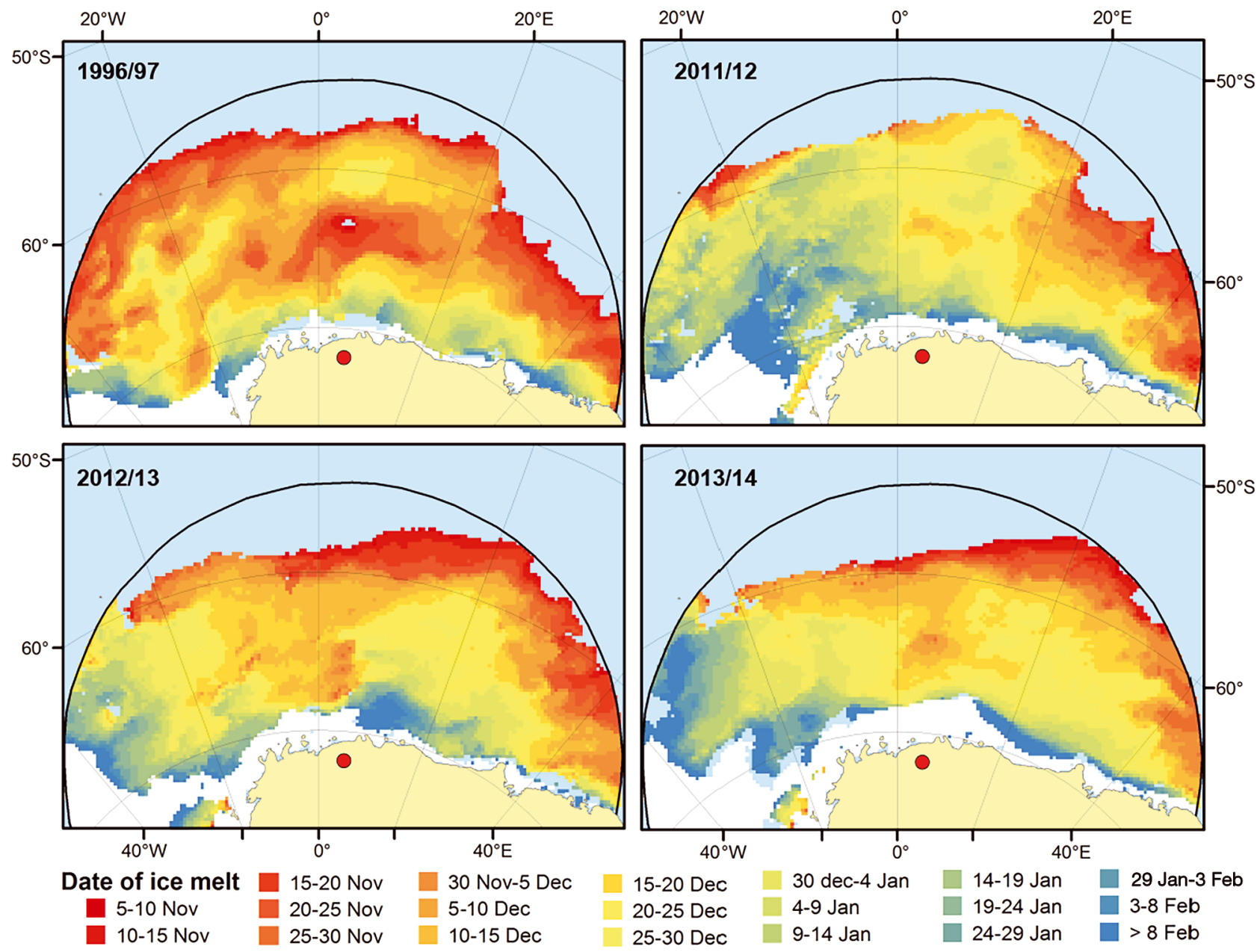

Fig. 4. Spatial pattern in date of ice melt within Antarctic petrel Thalassoica antarctica foraging habitat in the 4 study periods. Foraging habitat (black arc) is defined as the ocean area within a radius of $2000 \mathrm{~km}$ from the breeding colony Svarthamaren (red dot). Light blue: areas with open ocean $(<15 \%$ ice) throughout the study period or areas where the date of ice melt was undefined (see 'Materials and methods'). White: ice cap or multi-year ice (>50\% ice cover on $1 \mathrm{March}$ )

medium ice cover (Fig. 6B). This was confirmed by separate GAM analyses with respect to time since ice melt for early (ice cover $>40 \%$ ), transitional (ice cover between 12 and $40 \%$ ), and late trips (ice cover $<12 \%)$. For early trips, the model yielded: adjusted $\mathrm{R}^{2}=0.20, \mathrm{n}=558$, edf $=5.1$; for the transitional trips: adjusted $\mathrm{R}^{2}=0.04, \mathrm{n}=1152$, edf $=6.8$; and for long (maximum distance to colony $>885 \mathrm{~km}$ ) and late trips: adjusted $\mathrm{R}^{2}=0.13, \mathrm{n}=712$, edf $=7.6$. The model (Fig. 6) suggested that, throughout the season, Antarctic petrels increased their search effort in melting areas, i.e. areas within $\pm 10 \mathrm{~d}$ of the defined date of ice melt. Thus, independent of the ice cover in the habitat, Antarctic petrels seemed to prefer areas where ice was actively melting. However, late in the season when the ice cover had diminished, and later phenological stages became available, Antarctic petrels also increased their effort in areas that had been ice-free for about 50 to $60 \mathrm{~d}$ (Fig. 6C).

\section{Foraging relationships with $\mathrm{chl}$ a concentrations}

The GAM of the standardized FPT as a function of chl a concentration and percentage ice cover in the habitat by the start of each trip showed a low and complex fit (adjusted $\mathrm{R}^{2}=0.02, \mathrm{n}=2941$, edf $=22.1$ ). Bootstrap analysis revealed weak and non-significant responses with respect to chl a throughout the season, i.e. the bootstrap confidence intervals of the predicted FPT overlapped for all values of chl a (Fig. 7), suggesting that Antarctic petrels in general were non-responsive to variation in the surface concentration of chl a.

\section{DISCUSSION}

Ice melt triggers the development of the Antarctic spring and summer open-water ecosystem, including 

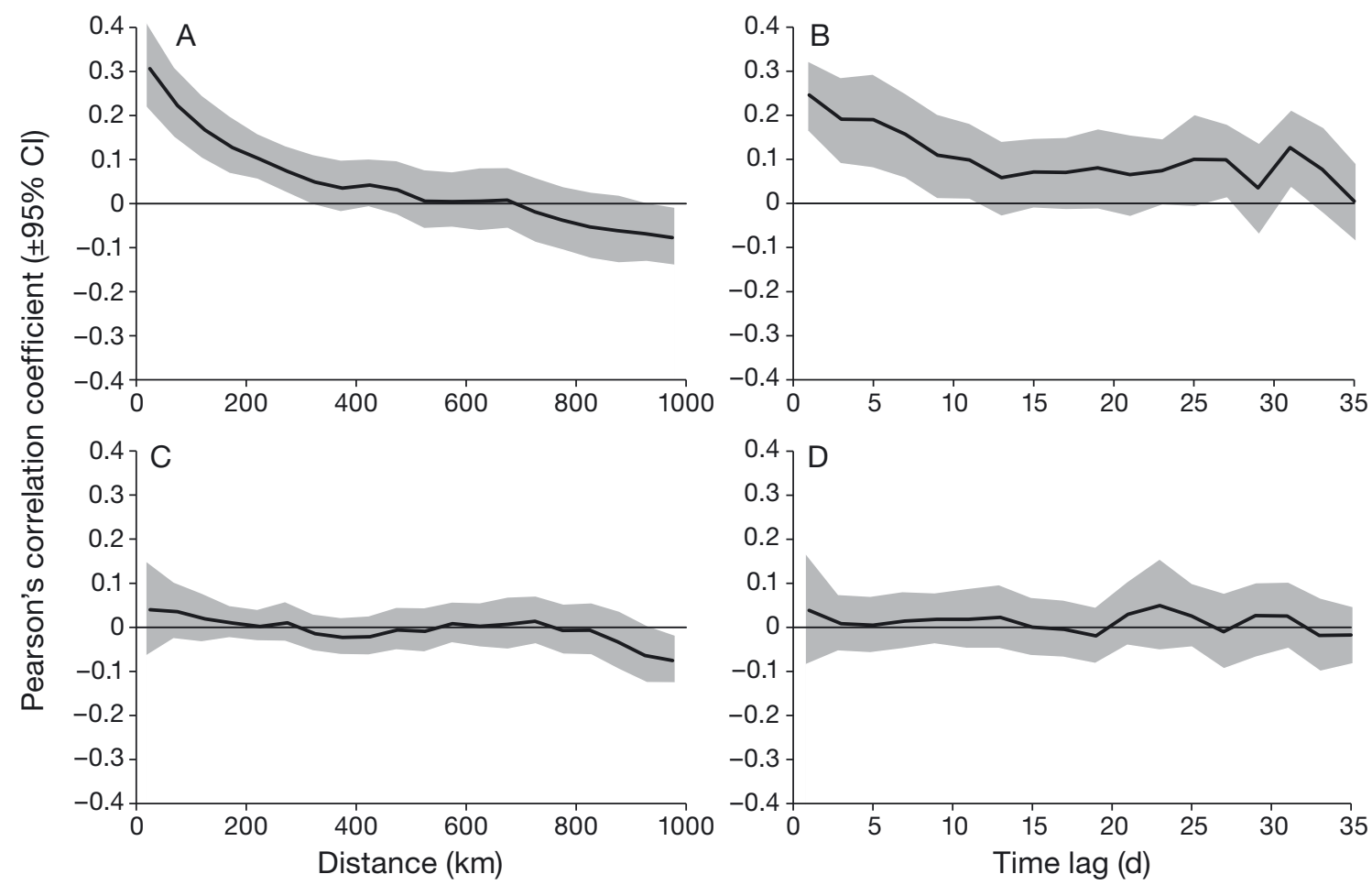

Fig. 5. $(\mathrm{A}, \mathrm{C})$ Spatial and $(\mathrm{B}, \mathrm{D})$ temporal cross-correlograms of standardized first-passage time among foraging trips of Antarctic petrels Thalassoica antarctica. $(\mathrm{A}, \mathrm{B})$ are cross-correlograms within breeding seasons while $(\mathrm{C}, \mathrm{D})$ are among breeding seasons. For the spatial cross-correlograms $(A, C)$, maximum lag between dates of observations was set to $2 \mathrm{~d}$. For the temporal cross-correlograms (B,D), maximum distance between observations was set to $100 \mathrm{~km}$. Grey areas: delete-one jackknife $95 \%$ CI with trip as the statistical unit

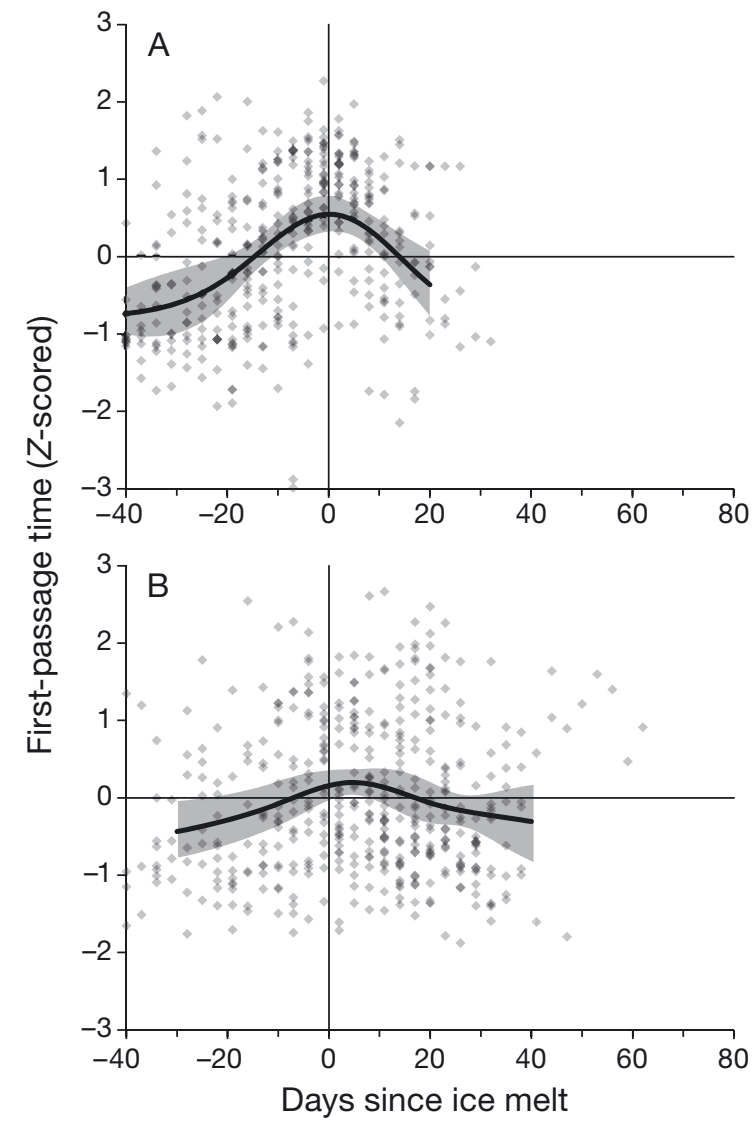

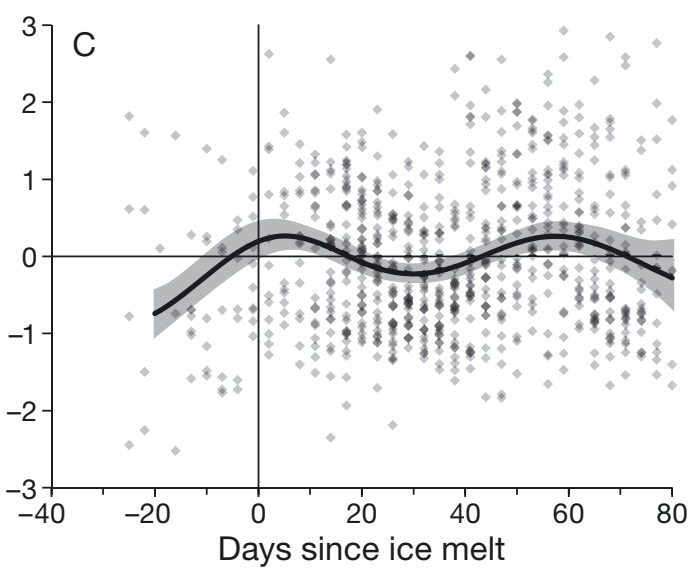

Fig. 6. Standardized first-passage time (FPT) of foraging Antarctic petrels Thalassoica antarctica as a function of time elapsed since ice melt at different seasonal stages of ice retreat (A: $50 \%, \mathrm{~B}: 30 \%$, and C: $10 \%$ ice cover). Thick lines: mean predicted values $\pm 95 \%$ CIs (shaded areas) from bootstrapped generalized additive models (GAMs) fitting standardized FPT to a 2-dimensional smoothing of days since ice melt and percentage ice cover in the available habitat at the start of the foraging trip. Data points: observations matching the corresponding intervals of percentage of ice concentration in the habitat 


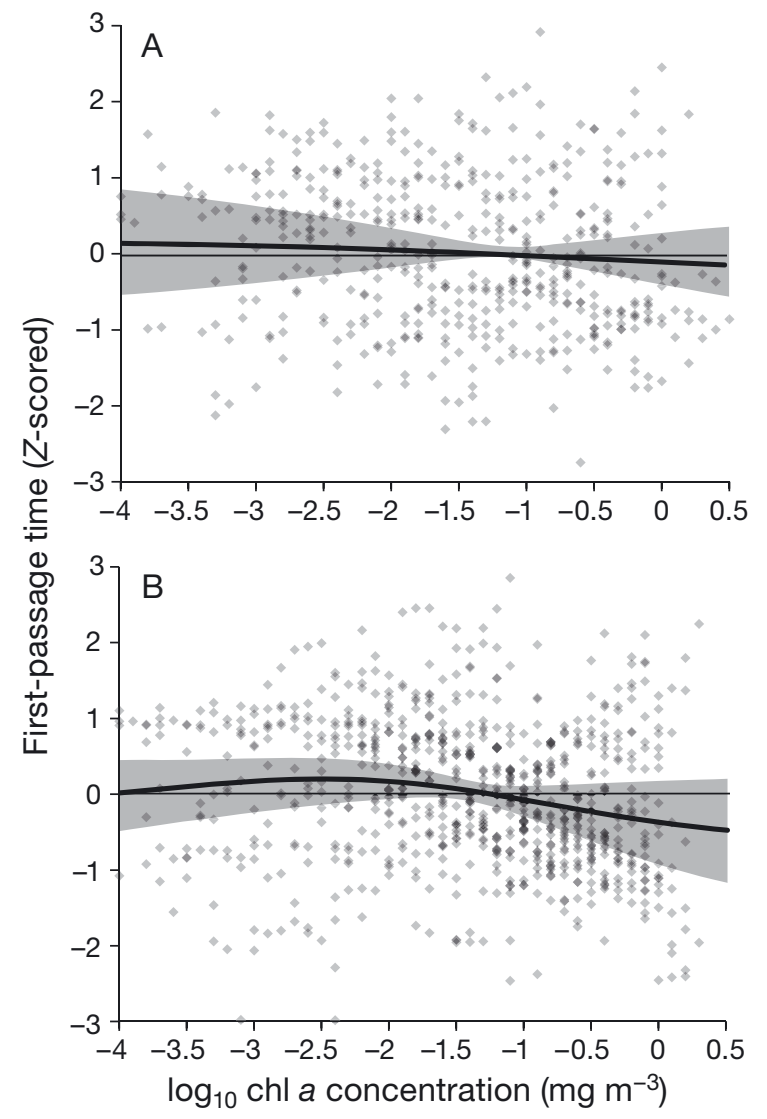

a short-lived phytoplankton bloom, the grazing and development of zooplankton, and the influx of foraging avian and mammalian predators (Brierley \& Thomas 2002, Fraser \& Hofmann 2003, Murphy et al. 2007). The retreat of the ice is patchy, and at a given date in spring, different areas have reached different stages in spring phenology, generating spatial heterogeneity in the habitat available to top predators. We show that Antarctic petrels responded to this heterogeneity by concentrating their search effort in melting areas, i.e. areas within $\pm 10 \mathrm{~d}$ from the date of ice melt, showing less interest for areas still heavily covered with ice and areas that had been ice-free for longer periods. Late in the season when the ice extent was at a minimum and older phenological stages became available, birds also selected areas that had reached an age of 50 to $60 \mathrm{~d}$ from the date of ice melt. In other words, the offshore-feeding Antarctic petrels seemed to prefer areas in specific phenological stages determined by the time of ice melt. As a result, their foraging areas changed as the season progressed, reflecting a transient and constantly changing habitat. Remotely sensed measures of chl $a$ indicated that the phytoplankton biomass increased rapidly after the ice melt, reached a maximum after 20 to $40 \mathrm{~d}$, and decreased thereafter. This pattern did

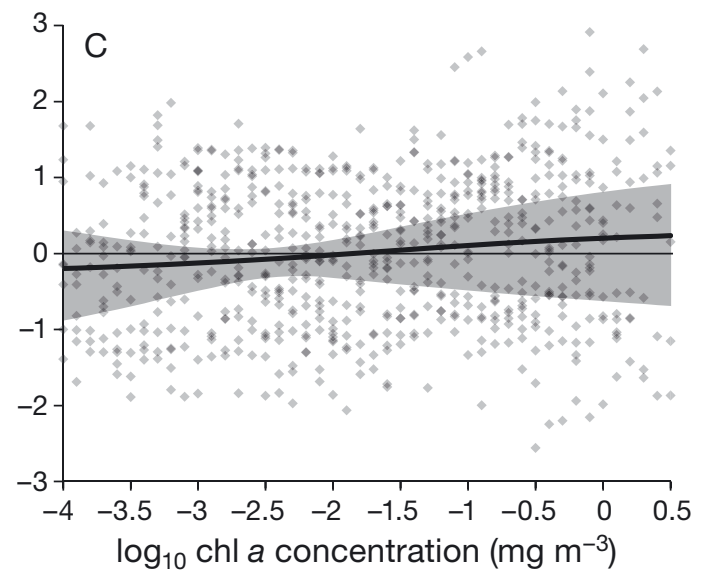

Fig. 7. Standardized first-passage time (FPT) of foraging Antarctic petrels Thalassoica antarctica as a function of remotely sensed chl a concentration at different seasonal stages of ice retreat (A: $50 \%$, B: $30 \%$, and C: $10 \%$ ice cover). Thick lines: mean predicted values $\pm 95 \%$ CIs (shaded areas) from bootstrapped generalized additive models (GAMs) fitting standardized FPT to a 2-dimensional smoothing of chl $a$ and percentage ice cover in the available habitat at the start of the foraging trip. Data points: observations matching the corresponding intervals of percentage of ice concentration in the habitat

not overlap with the phenological stages selected by the Antarctic petrels, and accordingly, we found no relationship between the foraging effort of the Antarctic petrels and remotely sensed chl $a$. In other words, areas with high phytoplankton biomass during the spring bloom maximum were not necessarily associated with favorable foraging areas.

The increased foraging effort in areas with melting ice supports the hypothesis that near-surface prey patches were more abundant in areas of an early phenological stage. Theory suggests that the vertical distribution of pelagic herbivores is determined by a trade-off between food availability and survival (Ohman 1990, Fiksen et al. 2005), and krill, the dominant herbivore of the Antarctic Ocean, is subject to the same trade-off (Alonzo \& Mangel 2001, Cresswell et al. 2009, Ainley et al. 2015). The ice-free surface layer is a high-gain, high-risk habitat, while deeper layers have both lower gain and lower risk (Kaartvedt 2010, Ainley et al. 2015). The spring development of the open-water ecosystem provides a predictable change in the abundance of both phytoplankton and meso-predators, and krill should change their position in the water column according to the most profitable depth (Ainley et al. 2015). The predation pressure from seabirds, pinnipeds, and cetaceans is expected 
to increase as the season develops, suggesting a progressively deeper position of krill (Ainley et al. 2015). Moreover, during the peak phytoplankton bloom, krill may become unable to convert the excess of highdensity food in the surface layer into increased growth (Atkinson et al. 2006), making it more profitable to stay below the risky surface habitat. These simple optimality considerations suggest that krill should be found closest to the surface, and more accessible to surface-feeding seabirds, early in the season before the peak in the spring bloom. This pattern has recently been documented in the Ross Sea (Ainley et al. 2015), and we suggest that the same mechanism might be responsible for the increase in search effort among surface-feeding Antarctic petrels in melting areas of the Weddell Sea in the present study.

Later in the season, Antarctic petrels also selected areas that had reached an age of 50 to $60 \mathrm{~d}$ since ice melt. We hypothesize that this behavior might reflect the opportunistic exploitation of a particularly profitable life-cycle stage of krill. One such candidate is gravid and spawning krill. Compared to the other life-cycle stages of krill, gravid krill are, due to their high lipid content, a highly profitable prey item for chick-rearing seabirds (Chapman et al. 2010). Several studies have shown that the maturation of female krill is closely linked to the retreat of the sea ice and the subsequent spring bloom (Quetin \& Ross 2001, Kawaguchi et al. 2007). Because krill need to utilize the algal bloom in order to complete maturation (Cuzin-Roudy \& Labat 1992), spawning takes place after the peak in the spring bloom, which would coincide with the Antarctic petrels' selection of a late phenological stage.

FPT analyses indicated that a large majority of Antarctic petrels (188 out of 191 trips) performed ARS. Cross-correlation analyses suggested that the common foraging areas were relatively large with an extent of $300 \mathrm{~km}$, short-lived (with a duration of 10 to $30 \mathrm{~d}$ ), and showed no detectable overlap among years. These characteristics limit the range of environmental factors that possibly could explain the formation of the foraging areas. Most importantly, they exclude environmental features associated with a fixed spatial location such as oceanographic features linked to bathymetry, while pointing towards unstable largescale features such as the spring bloom and the large-scale melting pattern of sea ice. Accordingly, within the Antarctic petrels' habitat, the date of ice melt ranged from 6 November to 15 February, showing a large-scale spatial pattern that differed markedly among years (cf. our Fig. 4; see also Massom et al. 2013). For Antarctic petrels, the transient and unpre- dictable nature of the heterogeneity provided by the melting ice, combined with possible interactions with other krill predators, underlines the importance of a wide-ranging and flexible foraging strategy. It suggests that foragers should respond directly to prey patches (Fauchald 1999) rather than relying on geographically or environmentally fixed foraging habitats. In other words, because foraging areas continuously change, the birds cannot rely on previous spatial information of where to search for food. Foraging decisions instead are likely based on real-time cues such as the observations of other foraging birds (Grünbaum \& Veit 2003) or odor cues of e.g. dimethyl sulfide released from heavily grazed phytoplankton (Nevitt et al. 1995, 2008).

A system where foragers constantly track moving and unpredictable patches of prey involves a highly stochastic and variable encounter rate, and one could therefore expect relatively large variation in the properties of individual foraging trips (e.g. trip duration, trip length, and ARS scale) and weakly defined foraging areas. Stochastic variation in foraging success might accordingly be an explanation for the large differences found in the ARS scale among trips ( 5 to $260 \mathrm{~km}$ ), the relatively weak correlation in foraging effort among neighboring foraging Antarctic petrels (cf. Fig. 5), and finally the relatively weak fit of the model explaining foraging effort by phenological stages (cf. Fig. 6). In fact, the weakly defined and elusive common foraging areas indicated by crosscorrelation analyses (Fig. 5) suggest a stochastic system where little variation could be expected to be explained by environmental variables. This does not imply that environmental factors are unimportant; it simply illustrates that the foraging strategy employed by Antarctic petrels produces stochastic noise in the relationships between the factors responsible for the formation of foraging areas and the behavioral responses detected by FPT. In addition to the stochasticity in foraging success, it is likely that non-foraging behavior such as resting might falsely indicate important feeding areas and thereby obscure the relationship between environmental variables and FPT (Sommerfeld et al. 2013). This would be especially important when the non-foraging activity occurs at specific locations (e.g. roosting places near the colony) independent of the feeding areas.

Temporal matches (or mis-matches) between food availability and predators are important elements of seasonal environments that heavily influence predator-prey interactions and food web structure (McMeans et al. 2015). In extreme seasonal environments such as the polar seas, mobile predators com- 
pensate for temporal variability with spatial flexibility. In this context, petrels and albatrosses are successful since they are exceptionally mobile and search very large areas of the ocean's surface for food. Our results suggest that the match between breeding phenology and the onset and development of melting ice, and the subsequent changes in the availability and profitability of prey, may be of importance to Antarctic petrels. In particular, we showed that Antarctic petrels utilize specific phenological stages, suggesting that the availability of these stages during breeding could be critical for breeding success. Indeed, for terrestrial herbivores tracking early phenological stages of plants during spring, it has been suggested that a diversity of altitudinal gradients in the habitat might be important to ensure a prolonged availability of the early and nutritious stages of plants (Mysterud et al. 2001). Similarly, we show that spatial variation in melting ice in the habitat of Antarctic petrels provides a range of phenological stages during the breeding period. For birds tracking vast areas in the search for prey, this diversity is particularly important, securing the presence of profitable feeding grounds throughout the breeding cycle. However, contrary to the predictable altitudinal gradients present in terrestrial habitats, the melting pattern in the Southern Ocean was relatively unpredictable and offered few fixed spatial gradients that could aid mobile foragers in tracking profitable phenological stages, i.e. 'moving with the spring'. The spatially variable annual ice melt pattern in the Southern Ocean shapes the development of a highly patchy and elusive food web underscoring the importance of flexible foraging strategies among top predators.

Acknowledgements. This work was supported by the Norwegian Antarctic Research Expedition program of the Norwegian Research Council (grant no. 2011/70/8/KH/is to S.D.). We are very grateful to our dedicated field assistants (S. Haaland, G. Mabille, T. Nordstad, E. Soininen, and J. Swärd). We thank H. Jensen for help with fieldwork in the 1996-97 season. We thank the logistic department at the Norwegian Polar Institute and the Troll Station summer and wintering teams for field support. N. G. Yoccoz gave valuable comments on earlier drafts.

\section{LITERATURE CITED}

Ainley DG, Ballard G, Jones RM, Jongsomjit D, Pierce SD, Smith WO Jr, Veloz S (2015) Trophic cascades in the western Ross Sea, Antarctica: revisited. Mar Ecol Prog Ser 534:1-16

Alonzo SH, Mangel M (2001) Survival strategies and growth of krill: avoiding predators in space and time. Mar Ecol Prog Ser 209:203-217
Atkinson A, Siegel V, Pakhomov E, Rothery P (2004) Longterm decline in krill stock and increase in salps within the Southern Ocean. Nature 432:100-103

Atkinson A, Shreeve RS, Hirst AG, Rothery P and others (2006) Natural growth rates in Antarctic krill (Euphausia superba): II. Predictive models based on food, temperature, body length, sex, and maturity stage. Limnol Oceanogr 51:973-987

* Bailey H, Thompson P (2006) Quantitative analysis of bottlenose dolphin movement patterns and their relationship with foraging. J Anim Ecol 75:456-465

Brierley AS, Thomas DN (2002) Ecology of Southern Ocean pack ice. Adv Mar Biol 43:171-276

Brierley AS, Fernandes PG, Brandon MA, Armstrong F and others (2002) Antarctic krill under sea ice: elevated abundance in a narrow band just south of ice edge. Science 295:1890-1892

* Chapman EW, Hofmann EE, Patterson DL, Fraser WR (2010) The effects of variability in Antarctic krill (Euphausia superba) spawning behavior and sex/maturity stage distribution on Adelie penguin (Pygoscelis adeliae) chick growth: a modeling study. Deep Sea Res II 57:543-558

Comiso JC (2000) Bootstrap sea ice concentrations from Nimbus-7 SMMR and DMSP SSM/I-SSMIS, version 2. http://nsidc.org/data/docs/daac/nsidc0079_bootstrap_ seaice.gd.html

* Cresswell KA, Tarling GA, Thorpe SE, Burrows MT, Wiedenmann J, Mangel M (2009) Diel vertical migration of Antarctic krill (Euphausia superba) is flexible during advection across the Scotia Sea. J Plankton Res 31: 1265-1281

Cuzin-Roudy J, Labat JP (1992) Early summer distribution of Antarctic krill sexual development in the Scotia-Weddell region: a multivariate approach. Polar Biol 12:65-74

* Descamps S, Tarroux A, Lorentsen SH, Love OP, Varpe Ø, Yoccoz NG (2016) Large-scale oceanographic fluctuations drive Antarctic petrel survival and reproduction. Ecography 39:496-505

Efron B, Tibshirani RJ (1993) An introduction to the bootstrap. Chapman \& Hall/CRC, Boca Raton, FL

*Fauchald P (1999) Foraging in a hierarchical patch system. Am Nat 153:603-613

* Fauchald P, Tveraa T (2003) Using first-passage time in the analysis of area-restricted search and habitat selection. Ecology 84:282-288

*Fauchald P, Tveraa T (2006) Hierarchical patch dynamics and animal movement pattern. Oecologia 149:383-395

* Fiksen O, Eliassen S, Titelman J, Fiksen Ø (2005) Multiple predators in the pelagic: modelling behavioural cascades. J Anim Ecol 74:423-429

*Forrest J, Miller-Rushing AJ (2010) Toward a synthetic understanding of the role of phenology in ecology and evolution. Philos Trans R Soc B 365:3101-3112

* Fraser WR, Hofmann EE (2003) A predator's perspective on causal links between climate change, physical forcing and ecosystem response. Mar Ecol Prog Ser 265:1-15

Freitas C, Kovacs KM, Lydersen C, Ims RA (2008) A novel method for quantifying habitat selection and predicting habitat use. J Appl Ecol 45:1213-1220

* Grünbaum D, Veit RR (2003) Black-browed albatrosses foraging on Antarctic krill: density-dependence through local enhancement? Ecology 84:3265-3275

*Hamer KC, Humphreys EM, Magalhães MC, Garthe S and others (2009) Fine-scale foraging behaviour of a mediumranging marine predator. J Anim Ecol 78:880-889 
Iversen M, Fauchald P, Langeland K, Ims RA, Yoccoz NG, Bråthen KA (2014) Phenology and cover of plant growth forms predict herbivore habitat selection in a high latitude ecosystem. PLOS ONE 9:e100780

Ji R, Jin M, Varpe Ø (2013) Sea ice phenology and timing of primary production pulses in the Arctic Ocean. Glob Change Biol 19:734-741

Kaartvedt S (2010) Diel vertical migration behaviour of the northern krill (Meganyctiphanes norvegica Sars). Adv Mar Biol 57:255-275

Kawaguchi S, Yoshida T, Finley L, Cramp P, Nicol S (2007) The krill maturity cycle: a conceptual model of the seasonal cycle in Antarctic krill. Polar Biol 30:689-698

* Lorentsen SH, Klages N, Røv N (1998) Diet and prey consumption of Antarctic petrels Thalassoica antarctica at Svarthamaren, Dronning Maud Land, and at sea outside the colony. Polar Biol 19:414-420

Massom R, Reid P, Stammerjohn S, Raymond B, Fraser A, Ushio S (2013) Change and variability in east Antarctic sea ice seasonality, 1979/80-2009/10. PLOS ONE 8:e64756

McMeans BC, McCann KS, Humphries M, Rooney N, Fisk AT (2015) Food web structure in temporally-forced ecosystems. Trends Ecol Evol 30:662-672

Mitchell BG, Holm-Hansen O (1991) Observations of modeling of the Antartic phytoplankton crop in relation to mixing depth. Deep Sea Res A 38:981-1007

Moline MA, Karnovsky NJ, Brown Z, Divoky GJ and others (2008) High latitude changes in ice dynamics and their impact on polar marine ecosystems. Ann N Y Acad Sci 1134:267-319

Murphy EJ, Watkins JL, Trathan PN, Reid K and others (2007) Spatial and temporal operation of the Scotia Sea ecosystem: a review of large-scale links in a krill centred food web. Philos Trans R Soc B 362:113-148

Mysterud A, Langvatn R, Yoccoz NG, Stenseth NC (2001) Plant phenology, migration and geographical variation in body weight of a large herbivore: the effect of a variable topography. J Anim Ecol 70:915-923

Nevitt GA, Veit RR, Kareiva P (1995) Dimethyl sulphide as a foraging cue for Antarctic Procellariiform seabirds. Nature 376:680-682

Nevitt GA, Losekoot M, Weimerskirch H (2008) Evidence for olfactory search in wandering albatross, Diomedea exulans. Proc Natl Acad Sci USA 105:4576-4581

O'Reilly JE, Maritorena S, Mitchell BG, Siegel DA and others (1998) Ocean color chlorophyll algorithms for SeaWiFS. J Geophys Res Oceans 103:24937-24953

Ohman MD (1990) The demographic benefits of diel vertical

Editorial responsibility: Rory Wilson,

Swansea, UK migration by zooplankton. Ecol Monogr 60:257-281

*Passos C, Navarro J, Giudici A, González-Solís J (2010) Effects of extra mass on the pelagic behavior of a seabird. Auk 127:100-107

* Phillips RA, Xavier JC, Croxall JP (2003) Effects of satellite transmitters on albatrosses and petrels. Auk 120: 1082-1090

พ Pinaud D (2008) Quantifying search effort of moving animals at several spatial scales using first-passage time analysis: effect of the structure of environment and tracking systems. J Appl Ecol 45:91-99

* Pinaud D, Weimerskirch H (2005) Scale-dependent habitat use in a long-ranging central place predator. J Anim Ecol 74:852-863

Quetin LB, Ross RM (2001) Environmental variability and its impact on the reproductive cycle of Antarctic krill. Am Zool 41:74-89

R Development Core Team (2016) R: a language for statistical computing. R Foundation for Statistical Computing, Vienna

Smetacek V, Nicol S (2005) Polar ocean ecosystems in a changing world. Nature 437:362-368

Smith WO, Nelson DM (1985) Phytoplankton bloom produced by a receding ice edge in the Ross Sea: spatial coherence with the density field. Science 227:163-166

Sommerfeld J, Kato A, Ropert-Coudert Y, Garthe S, Hindell MA (2013) Foraging parameters influencing the detection and interpretation of area-restricted search behaviour in marine predators: a case study with the masked booby. PLOS ONE 8:e63742

Stammerjohn SE, Martinson DG, Smith RC, Iannuzzi RA (2008) Sea ice in the western Antarctic Peninsula region: spatio-temporal variability from ecological and climate change perspectives. Deep Sea Res II 55: 2041-2058

* Tarroux A, Weimerskirch H, Wang SH, Bromwich DH and others (2016) Flexible flight response to challenging wind conditions in a commuting Antarctic seabird: Do you catch the drift? Anim Behav 113:99-112

*Vandenabeele SP, Shepard EL, Grogan A, Wilson RP (2012) When three per cent may not be three per cent; deviceequipped seabirds experience variable flight constraints. Mar Biol 159:1-14

*Visser ME, Both C (2005) Shifts in phenology due to global climate change: the need for a yardstick. Proc R Soc B 272:2561-2569

Wood SN (2006) Generalized additive models: an introduction with R. Chapman \& Hall/CRC, Boca Raton, FL

Submitted: April 19, 2016; Accepted: February 7, 2017

Proofs received from author(s): March 10, 2017 